\title{
Optimization of Costs Determined by the Application of the Quality Management System
}

\author{
Ion Ionita Ph.D. \\ Academy of Economic Studies-Bucarest \\ Florin-Aurelian Popescu Ph.D. \\ University "Valahia" Targoviste \\ Costel Șerban \\ Ph.D. Student Assistant \\ Academy of Economic Studies-Bucarest \\ Dr. Diamandescu Andrei \\ Assistant \\ University Nicolae Titulescu-Bucarest
}

\begin{abstract}
The subject approached in this article concerns and optimization of costs so that integrated quality management systems could be applied. The optimization implies in this case that a limit should be ascertained for costs that are generated by the implementation and operation of the system so that such limit could be used as a basis for obtaining a maximum of benefit or, in other words, a minimum cost should be determined to which the business of the company can be materialized in such results that are foreseen upon the implementation of the system. In order that optimization could be possible, one must know such costs first of all, while corporate practice suggests that such requirement is difficult to fulfil. At present, circumstances are even more complicated, as most industrial corporations apply integrated quality systems in which, beside the standard ISO 9001, other two or several other ISO standards have been further implemented. In this case, the recording and optimization of quality costs becomes much more complex, less precise and more expensive. This is why cost optimization by mathematical modelling, which is both the most precise and the most complex method, is less affordable, meaning that business agents, in their practice, prefer a simpler method, that of comparing the performance of the organization with a reference standard (for example ISO 9001), which captures the difference to the performance before a quality system was implemented. In this context, authors suggest that the second method (i.e. that based on comparisons) should be selected. For its application, they have prepared a methodology for which feasibility was based on the results of a research made in several companies in Romania.
\end{abstract}

Keywords: optimization, cost of quality, econometric model, quality system, standard

\section{JEL Classification: M11, G32}

\section{Introduction}

The integration of quality management systems has begun to be a priority for companies that intend to apply two or several quality standards. Many organizations have already implemented an integrated quality system, which, due to its synergy effect, ensures both an improvement of their efficiency and a maximization of the quality in the processes of such organization. In such context, the objectives of our research reside in an assessment of difficulties and benefits of an Integrated Quality Management System (IQMS) and on this basis, the planning of a general system template that would include methods of continuous quality improvement belonging to Kaizen management system, which we have called "the Integrated Management System for Continuous Quality Improvement (IMSCQM)". Apart from that, we also intend to prepare a methodology for the implementation of such template, which should be aligned to BSI PAS 99 and the guidelines ISO 83. 
The template we are going to suggest will have a significant impact on the harmonization of standards make up the integrated quality system and due the fact that the new standards (edition 2015) have the same structure, they can be read and understood more easily and they will allow an extension of the use of IMSCQM, thus offering significant added value for companies, practicing and consultants. Corroborated with such two objectives, we shall also express our opinion on the impact of the implementation and use of IMSCQM on organization performance and hence the need of rendering it general for the entire economy.

The research we have carried out in several industrial companies had as result the fact that, due to the implementation of an integrated quality management system, the efficiency and competitiveness of enterprises have certainly improved. All the same, such improvement is far better in case of enterprises that have implemented together with IQMS also methods of the Kaizen system of continuous quality improvement. Such new model of quality management is superior to current systems, due to its greater effect on the increase of corporate efficiency. The efficiency increase is determined by the conjoined action of the effect of synergy triggered by the use of several standards, on the one hand and of the methods belonging to Kaizen management system. Apart from that, the basic meaning of the word KAIZEN, which means continuous improvement, implies a continuity of managing towards improvement, which is essential for performance.

Apart from that, the use of IMSCQM also helps to the improvement of relations and interference processes between people. If we learn to set things in a certain order, the process of conducting an activity becomes a reflex, doing it at a higher speed and with less effort, thus becoming more efficient. For example, if we apply the method $5 \mathrm{~S}$ in an office, we shall generate order and efficiency in everything that we do. Apart from that, the combined application of certain methods of KAIZEN management system also implies responsibility, not just competence. This is dual: competence means to know how to do a certain thing and, at the same time, to be responsible for what you do. The application of methods allows us to find solutions so that we could be better today than we were yesterday and moreover, to get prepared so that we could be better tomorrow than yesterday. This is why, related to Kaizen philosophy, a certain rule must exist and operate for the entire corporate staff: "I come to work to do my job and make improvements". This implies that one must permanently wonder: "How can I do my work better? How could I eliminate a mind-set that makes me think that my current approach is the best? I should become aware that I an evolving being, continuously learning from the relationship with the environment, that I am a creative being!".

These are the results of IQMS application, combined with KAIZEN methods. As a result, it is our opinion that, in the future, all companies that introduce a quality management system will assimilate such new system IMSCQM. Our suggestion is that methods belonging to the Kaizen system for continuous improvement of quality should be included in IQMS, which is actually considered a quality system in its own right. Our proposal is based on an analysis of the real results we have found in the research we have conducted in the companies where such system is implemented. By this, we refer to the fact that, in most such enterprises, the quality system used IQMS does not offer results that would ensure any significant progress of competitiveness. We would also like to point out that the system itself does not cause any fault, but the fact that the managers of enterprises where such system is implemented do not take the proper measures to introduce methods by which system capabilities could be adequately activated, because they do not understand its requirements properly. This is why we consider that IQMS should be considered a stage of IMSCQM and that only by its implementation in full, starting with the standards of ISO family, results could get to a maximum.

\section{The use of methods of continuous quality improvement in Romanian industry and an analysis of their efficiency}

In Romania, most organizations that have implemented a quality management system based on the standard ISO 9001 do not manifest any constant preoccupation for parallel implementation of methods that would create the premises for fulfilling the principle of continuous quality improvement. This explains the unsatisfactory results of several of such companies. The certification of the quality system of an organization, based on ISO standards, does not mean that, automatically, all the goods and services they deliver exclude any deviation from established requirements. Such a certificate can only prove that conditions have been fulfilled for the carrying out of processes in the organization, starting with market research and up to the surveillance of products under operation at the beneficiary, so that they fulfil the prerequisites imposed by certification. After certification, one must take care that referential requirements should be complied with by continuous efforts of improving all processes. 
To this end, it is necessary that, apart from ISO standard, one must implement, as shown, also specific methods for improving the quality of processes taking place in the organization, while avoiding any appearance of irregularities on the entire chain of goods production and operation. After an analysis of the facts in Romania, we have found in this respect, first of all, that the number of ISO certificates is small as compared to other countries. According to the report ISO-WORD (Product Activation Failed) from 2015, the facts are presented in the table no. 1. Report on certifications worldwide and at the level of certain countries at the end of the year 2015

Table no. 1

\begin{tabular}{|c|c|c|}
\hline & No. of certificates worldwide & Evolution of certifications on the top first countries \\
\hline ISO 9001 & 1033936 & $\begin{array}{l}\text { Italy (128796), UK (39950), Spain (112525), Germany (41346), India } \\
\text { (36263), Romania (20504) etc. }\end{array}$ \\
\hline ISO 14001 & 319324 & $\begin{array}{l}\text { Italy (22225), UK (17778), Spain (13180), Germany (8180), India (36263), } \\
\text { Romania (10571) etc. }\end{array}$ \\
\hline ISO 50001 & 11985 & $\begin{array}{l}\text { Italy (470), UK (1464), Spain (390), Germany (5931), India (405), Russia } \\
\text { (118) etc. }\end{array}$ \\
\hline ISO 27001 & 27536 & $\begin{array}{l}\text { Italy (1013), UK (2790), Spain (676), Germany (994), India (2490), Romania } \\
\text { (1078) etc. }\end{array}$ \\
\hline ISO 22000 & 32061 & $\begin{array}{l}\text { Italy (818), Poland (667), Japan (1089), Russia (733), India (2071), Romania } \\
\text { (1171) etc. }\end{array}$ \\
\hline $20000-1$ & 2778 & $\begin{array}{l}\text { Italy (86), UK (197), Spain (231), Germany (108), India (425), Czech } \\
\text { Republic (90) etc. }\end{array}$ \\
\hline
\end{tabular}

Apart from that, the analysis has also shown the fact that there are nevertheless preoccupations for the preparation of viable strategies that could ensure the survival of organizations, even in a turbulent environment such as the one in Romanian economy at present. In fact, in a turbulent business and financial environment with unpredictable evolutions, there are not only risks but also development opportunities that are hard to imagine in a stable economy. In this context, we consider that the present moment is propitious for managers of Romanian companies so that they could initiate vigorous actions for the implementation of management methods and techniques, which, if applied, could ensure them a substantial increase of business efficiency, regardless of the existence of disturbing factors from outside. We are referring herein precisely to the methods and techniques that are specific for Kaizen quality management system, such as: Kanban, Kano Model, 5S, Six Sigma, Lean, Value Engineering etc.

Regarding the management system bearing the name KAIZEN, the success of which has been proven in Japan, the analysis we have made pointed out the fact that there are major concerns in Romania regarding its awareness and use in enterprises. There have been set up many consulting companies in this field, including a Kaizen institute with important achievements in the implementation of the system. In an interview given to the on-line publication DC NEWS by the chairman of Kaizen Institute Romania, Julien Bratu, he maintained that the companies using Kaizen Management System in Romania were continuously expanding. At present, there are 22 companies that are part of the group "Kaizen Manager Club Association with over 17,000 employees. The turnover is of over 1,700 million euro, which means that more than 1\% of the GBP of Romania has been obtained by companies using Kaizen.None of these companies has had any loss during the crisis from 2008-2009 but, on the contrary, they developed. Another interesting fact is that related to the cost of implementing a Kaizen program, which is generally $1 \%$ of the corporate turnover"

As a result of the research I have made in Romanian companies, which have implemented, along with IQMS also further methods of Kaizen management system, the conclusion was that the generalized implementation of IMSCQM in Romanian businesses might lead to immediate gains due to a significant elimination of waste and losses, increase of labour productivity by approx. 20-30\% and a cut of operating costs by 15-20\%, as a result of reducing surfaces used, necessary equipment and an increase of the degree of using the remaining equipment, as well as a better staff motivation. To this end, nevertheless, factors hindering the implementation and obtaining of proper results should be eliminated from Romanian organizations.

\footnotetext{
${ }^{1}$ Julien Bratu, Country Manager of Kaizen Institute of Romania, - interview granted to the on-line publication DC NEWSin December 2014, published in January 2015.
} 
Among these, the highest influence is attributed to mentality, the psychological profile of Romanian managers and employees, as well as from other countries in Europe, which fail to support the fulfilling of the requirements of such type of management. By this, we refer to the mind-set and behaviour of managers regarding quality insurance. We have found that many managers are reluctant regarding the quality system, as they consider it an investment that is not covered by results, and that quality per se is a cutback of labour productivity. Such conclusion, which is obviously wrong, is due to the fact that they cannot calculate the efficiency with which quality systems would work in their businesses (and, as a result, they cannot analyse and substantiate their decisions in the field of quality). The cause resides in the lack of any method that would be adequate for such activity.

In order to find out the manner in which an integrated quality management system was implemented and its efficiency, after it has been combined with methods from the Kaizen system, I have performed a documentation research in several enterprises from Romania: Cris-Tim, ASSA ABLOY, Hirschmann Automotive Romania,Arctic-GaestiTargovișteEldon Romania,Pirelli Romaniaetc. As we shall further put forward, all these business have had remarkable results with respect to labour productivity, cost cutbacks and increase of competitiveness.

Cris-Tim, a leader of the Romanian cold cuts market, finished the year 2015 with an estimated group turnover of approximately 384 million euro, $15 \%$ more as compared to 2014, and it has an operating profit ratio (EBITDA) ${ }^{2}$ of $10 \%$, which is higher in respect to the previous year. As regards the cold cuts line of the group, this is represented by two companies with very good performances in 2015 , with results that are higher by $20 \%$ as compared to 2014.

Apart from its technical equipment and the most modern processing technologies, at the time when we carried out our research, Cris-Tim had already implemented an integrated quality management system made up of the standards ISO 9001:2008, ISO 22000:2005 and ISO 14001:2005. The results of applying such standards have been satisfactory and the quality of products / services improved, with a small cut of production costs. The management did not settle for such results and they initiated a project with the Kaizen Institute of Romania, for the implementation of Kaizen methods that would ensure a more extensive development of quality and group competitiveness. As a result of the audit performed by the specialists of the Kaizen Institute of Romania, a „road map" has been established, which lead to a training programme, specific activities and action plans for the implementation and development of a management system customized for Cris-Tim, which would ensure the implementation of the principle of continuous improvement.

The project started by the redefining of the mission, vision and strategy based on the method HoshinKanri ${ }^{3}$. A system of suggestions has been implemented, along with an improvement of the customer-supplier relationship, 5S, Auto Quality Matrix, standardization, Muda identification etc. The first opened sites and the first methods of continuous quality improvement have been applied in sausage factories, where the operating staff is accustomed to the implementation and compliance with standards that are specific for food industry. From the moment such process was initiated for the purpose of shifting mentalities and changing the manner of approach and problemsolving (March 2014), productivity increased by 30\% as compared to 2013. At the end of 2015, the turnover increased by $15 \%$ and the operating result (EBITDA) increased by $50 \%$.

By the implementation of methods of Kaizen management system, conditions have been created that allowed the group Cris-Tim to strictly follow a strategy of sales and production performance increase, as well as cost optimization, thus ensuring a maximization of financial results. AssaAbloyis a world leader in the field of solutions for door opening and closing.

The group ASSA ABLOY offers the most complete set of door opening solutions, as compared to any other company on the market. The division has 12,500 employees and its management is based in London. In 1998, the

\footnotetext{
${ }^{2}$ EBITDA - key financial performance indicator of companies expressing: earnings before interest, taxes, depreciation and amortization;

${ }^{3}$ HoshinKanri- strategic planning method. Teams gather data regarding current performances, they identify present customers and their needs. Strengths, weaknesses, opportunities and threats are analysed. Missions and vision are reviewed and adjusted, measures are established so that Hoshin organizational success is ensured. Hoshin - style strategic planning is based on standard planning in several ways: focus degree, engagement on all organizational levels, use of planning and tools for process improvement.
} 
group opened a branch in Romania: "ASSA ABLOY Romania. A prerequisite for the assurance of a market share that is a large as possible resides in the compliance with quality requirements, including product delivery deadlines. In order that such requirements could be fulfilled, an integrated quality system has been implemented based on the standards ISO: 9001, 14001, 26000.

Although results in the field of quality improved, the objective of the group of making ASSA ABLOY Romania a world leader in the field of door latch production for high value projects has not come to fruition, so that it could occupy the most important place on European, American and Australian markets. Due to these reasons, the management of ASSA ABLOY Romania has decided, based on the consent and investment support of the central management of the group, to implement methods of Kaizen Management System as well. The actual implementation of Kaizen system methods started in 2009. The main change factor was the real engagement of the company management, which established a coherent strategy that was consistent with market requirements. Based on such new strategy, programs have been developed for the implementation os system methods such as: 5S, Visual Management, Total Productive Maintenance and Total Service Management. Such important measures of consolidating the newly built structure also materialized in the preparation of a Manual of Roles and Responsibilities as well as of the System of Appreciation and Compensation based on accomplished performances.

The actual application of such methods together with IQMS has lead as early as the year 2011 to an increase of turnover by $33 \%$, reaching a profitability ratio of $17 \%$ as compared to $5 \%$-which has been reached before starting such implementation - and the doubling of the turnover.

Hirschmann Automotive is a car component producing company with the headquarters in the place of Rankweil in Austria. The company owns a production unit in Romania. Set up in 2007, Hirschmann Automotive Romania produces cabling for parking and battery sensors, mirror cablings, cables for automatic gearboxes and engines. The entire production of Hirschmann Romania is exported and the final customers are the main producers of cars and subsets in the automotive industry: Daimler, BMW, VW/ Audi, Chrysler, IVECO, Ford, Fiat, Renault etc.

At the time of our research, such business was certified based on the integrated quality management system according to the standards ISO TS 16949:2009, ISO 9001:2008 and ISO 14001:2005. Starting with 2012, Hirschmann Romania has undergone a programme of technical and management modernization and production assortment reconversion. In order that such program could be materialized, investments of 5 million euro have been assigned. This has implied the purchase of a large number of injection machines. In order that maximum efficiency could be ensured on an organisational level for the new technic equipment, it has been decided that Kaizen management system methods should be implemented, for which an agreement has been concluded with Kaizen Institute of Romania. The Method 5S and the Autonomous Maintenance Program have been implemented. The combined results of the investment program and of the quality system generated the following figures: in 2014, the turnover increased by $25 \%$ and labour productivity increased by $40 \%$ as compared to 2012 . S.C. ARCTIC S.A.-Găeștiwas incorporated in 1968 and shortly thereafter, it became a leader on the Romanian household appliance market as well as a trusted brand that was appreciated in Europe. After such privatization (in 1997), it became a part of a renowned company, the Turkish group Arçelik.

The evolution and the meaning of Arctic brand took shape and consolidated in time; at present, it is the third European producer and distributor of electric and household appliances, which is famous and appreciated on an international level.

At the time of our research, the company had already implemented an integrated quality management system ISO 9001:2008, ISO 1401:2005 and ISO 50001:2011. The company has also implemented methods of continuous quality improvement, among which 6 Sigma, Total productive maintenance and Just in Time. The results they have obtained will be presented under the point 5 .

In conclusion, all these actual results obtained by Romanian companies that implemented together with the integrated quality management system further methods for a continuous improvement of quality as well, are compelling arguments proving that the quality of products has improved substantially and that the efficiency and competitiveness of such companies has substantially increased.

This is why we consider that IMSCQM is superior to the present quality system IQMS and that the generalized implementation of such former system is a safe solution for increasing competitiveness. 


\section{Methods for the optimization of quality management system costs}

\subsection{Method of quality cost optimization based on econometric models}

The application of a quality system in an organization will generate costs and benefits. This is why the implementation decision is based on the criterion of business sufficiency i.e. of the impact that the implementation and functioning of such system will have on company performance. This implies the reaching of a minimum cost for a certain benefit rate. We can determine such impact based on econometric models involving a research on cost-quality correlations. In this case, cost optimization is a typical problem of mathematical analysis, the function of which, as reported to the aimed objective, can be of maximum or minimum, as follows: it could be a mathematical function $\mathbf{F}$, for which a set of values $\mathbf{V}$ is available belonging to the string of real numbers $\mathrm{R}$, whereas $\mathrm{X}_{0}$ is an element of the string $\mathrm{R}$, so that the minimization of cost for an expected result or the maximization of results to a set cost may be defined as:

(1) $F\left(X_{0}\right) \leq F(x)$ For minimization,

(2) $F\left(X_{0}\right) \geq F(x)$ For maximization.

The function $\mathrm{F}(\mathrm{x})$ is called the target function or the cost function. The conclusion is that, in order that costs of the quality management system could be improved, the cost-benefit model could be used, which, according to the relations (1) and (2) is rendered by the relation:

$$
\mathrm{UNV} / V N A=\sum_{n=1}^{D} \frac{(B-C)}{(1-r)} \text { whereas: }
$$

$[\mathrm{n}=1 \div \mathrm{D}]$

UNV - updated net value; $\mathrm{B}$ - value estimation of results; $\mathrm{C}$ - costs; $\mathrm{r}$ - updating ratio; $\mathrm{n}$ - year of referenced perspective analysed in years. The target is that of maximizing UNV (or VNA), which means the same as determining minimum costs. The quality that is generated by the standard ISO 9001 can by analysed for a term extending over a year. As a result, in order to calculate the sum in the equation (4) we shall include such year multiples, i.e. $\mathrm{UNV}_{0}, \mathrm{UNV}_{1}, \ldots \mathrm{UNV}_{\mathrm{D}}$ for $\mathrm{n}_{1}$ to $\mathrm{n}_{\mathrm{D}}$. Such string of $\mathrm{UNV}$ data allows us to establish how well the resulting UNV value corresponds to the suggested limit (E). The best analysis can be achieved by the chi-square test, for which the computational relationship is as follows:

(4) $X^{2}=\sum \frac{(O-E)^{2}}{E}$, Whereas

$\mathrm{O}$ - Registered value; $\mathrm{E}$ - value suggested for UNV

The string $\mathrm{UNV}_{1}, \mathrm{UNV}_{2}, \ldots, \mathrm{UNV}_{\mathrm{D}}$, includes the highest $\mathrm{UNV}$ value, which results when the maximum $\mathrm{UNV}$ was produced to the smallest cost, i.e. the optimal cost. We shall use resulting UNV value as a scale for comparison against the suggested UNV (UNVE). If such value corresponds to the relationship max $\mathbf{U N V}>\mathrm{UNVE}$, then the cost corresponding to such UNV is the optimal cost.

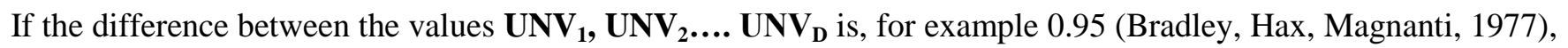
a trusted interval for UNV values at the moment $n_{1}, n_{2}, \ldots n_{D}$ to a degree of freedom 4 (I have considered a term of analysis of 5 years so that cost optimization could be confirmed), then chi-square values of analysed variables should be equal to or higher than 9.50. The optimal cost is placed on the point of analysis for which the value of difference is higher than 9.50 .

The literature in this field includes several econometric models by which the quality system cost could be optimized. In this respect, we mention here the models Juran, Schneidermann and the improved econometric models ISO, Six Sigma etc. The use of such models requires first and foremost that one should first of all obtain several types of statistical data regarding the evolution of costs and the quality level.

Quality costs shall be further compared to the business quality effects that might result from the following: resource saving, net income increase determined by an increase of the volume of sales, an increase of unit prices and a decrease of product unit prices, all such results determining a significant increase of competitiveness. 


\subsection{Method of quality cost optimization by an analysis of evolution of key performance indicators}

If in case of the quality management system - IQMS, the impact can be measured by comparing the organization performance to a reference standard that captures the difference to the performance before IQMS implementation, or by the optimization of quality costs with the help of the econometric models we have presented, in the case of the integrated system of continuous quality improvement we have proposed, efficiency / performance shall be measured by a methodology based on an analysis of key performance indicators of the organization. We suggest such orientation based on the findings from businesses where we have documented and where the decision of quality system implementation that is based on an optimization of costs by using econometric models is not agreed by the management. In this respect, we may offer as a typical example the answer of the chairman of S.C. Cris-Tim S.A. to our inquiry concerning the method of calculation and analysis on quality costs: "We do not calculate distinctively the costs of quality and we do not analyse separately their efficiency. If the evolution of financial indicators is in a continuous evolution, it is enough for us to consider that the impact of the quality system is favourable, i.e. an instrument that increases our competitiveness. It is not necessary for us to increase bureaucracy and costs".

The results of our research have outlined a few situations that justify such position of managers in this case, as follows:

* the real facts of industrial enterprises show that the quality system based on the standard ISO 9001 is outdated as all industrial businesses have been applying integrated quality systems for several years now, among which, apart from ISO 9001, other two or numerous other ISO standards have been implemented. In this case, the recording and optimization of quality costs becomes much more complex, less precise and more expensive;

* by the implementation of the quality system based on ISO standards, a certain improvement of business efficiency and competitiveness took place. The improvement is nevertheless superior by far in case of businesses that have applied the integrated IQMS system combined with methods of the continuous quality improvement system - Kaizen. This is why, in case of the generalization of the integrated management system for continuous quality improvement - IMSCQM, the recording of costs and their optimization becomes very complicated.

As we consider that most industrial businesses will turn to such new quality system - IMSCQM in the near future, an analysis methodology should be prepared so that its implementation could be rendered effective. Such methodology is could be most appropriately based on the evolution of key performance indicators, respectively, in our case, business financial indicators.

\subsubsection{Analysis indicators of business efficiency of the integrated management system for continuous quality improvement}

The main objective of the implementation of a quality management system resides in the increase of organization performance. Generally, performance is associated to two key processes - performance management and its measurement. The measuring of performance appears as a sub-process of performance management, which is mainly focused on the identification, follow-up and communication of performance results using key performance indicators. In order that performance could be measured for businesses, processes and projects that are essential within the organization, Key Performance Indicators are recommended. Such indicators are basic elements of the process of measuring and monitoring performance, by which results of certain activities are quantified, offering visibility in relation to organizational performance. Usually, a KPI-type indicator is expressed by percentages or averages and they must offer an answer especially to the question "why?". Not everything that can be measured represents a key performance indicator. For instance, the fact that 20 failed products have been found is not a KPI, but the fact that the level of failed products increased by $25 \%$ and that orders have not been placed anymore because of the customers' lack of trust is a KPI.

As a result, key performance indicators are quantitative measures, both financial and non-financial, regarding the performance of such tasks, operations or processes that are essential within the organization. The most frequently used key performance indicators are financial, yet the main indicators under focus vary depending on the industry. Although ratios for measuring financial and business performances of an enterprise are concern past performance, they have an informational content that is very useful in business analysis. 
As a result, business efficiency, which is determined with the help of financial performance indicators, expresses in the context of attributes that are characteristic for the model insider ${ }^{4}$ precisely the result of the quality system implementation which is substantiated in the continuous improvement of products, processes, activities and adequate engagement of motivated staff, depending on the degree of fulfilment of established targets, as well as the satisfaction of a number of customers that corresponds to business capacities and environment protection objectives.

In order that our analysis could be useful and suggestive in expressing the objectives we have followed in the case study to be presented below, under the following point, I have attentively selected key performance indicators choosing those that supply the competitive advantages that are generated by the management system, are directly related to performance, are measurable and ensure comparability to various references. As a result, in order to distinctively point out the contribution of the implementation and operation of quality systems in the improvement of business and financial results of the analysed company, we have used the following key performance indicators: Turnover (TO), variable costs, Variable Cost Ratio (VCR), Fixed Costs, Operating Profit, Breakeven Point (BEP), Term of Return on Investment (T), Return on Investment (ROI), Updated Net Income (UNI) and Rate of Return (R).

\subsubsection{Research method description}

Research for the preparation of methodology has concerned the impact of the integrated system made up of the standards ISO 9001:2008, ISO 14001:2005 and ISO 50001:2011, as combined with several other methods belonging to Kaizen system, on the financial performance of the analysed enterprise. Obviously, such research also benefitted from the documenting we have performed in other businesses in processing industries (ASSA ABLOY, Pirelli from Slatina, Eldon Romania, Star Transmission Cugir, Cris-Tim etc.), which has determined us to consider that the results of the research conducted at this company can be generalized at the level of the entire processing industry.

The research is based on extensive research combining questionnaire-based research aiming at an identification and selection of a sample of business that have implemented a quality system, on the one hand, with an empirical analysis of financial data gathered from such enterprises and a direct examining of financial data that have been made public by such companies, on the other hand.

The basic concept used in such research adapts the methodology of research of the insider model (customarily used in empirical corporate finance) so that they allow the separation of the impact of the quality system from that of other measures applied in the organization. Insider is at the same time a model that is based on human relations (relationship based system), which reflects the cultural diversity of the European Union ${ }^{5}$. We refer here to the specificity of enterprises in this geographical area that also encompasses the businesses of our country, as materialized in adopted quality policies as well as preoccupations so that complex objectives could be fulfilled, such as social responsibility programs and a special interest for pursuing a type of business that is sustainable from an environment protection point of view.

Apart from that, we take into consideration another characteristic of the group of enterprises that we have researched, i.e. that both the researched event and the moment it takes place can be certainly defined without any difficulty (for example, the obtaining of a quality assurance certificate). I have pointed out such final aspect due to the fact that there are numerous cases in which it is very difficult to ascertain with precision whether a research targeted event has occurred, due to the fact that the business is not set up on serious grounds and one cannot trust the public statements that its representatives make.

\footnotetext{
${ }^{4}$ In labor economics, the insider-outsider theory examines the behavior of economic agents in markets where some participants have more privileged positions than others. The theory was developed by Assar Lindbeckand Dennis Snower in a series of beginning in 1984.The insiders are those incumbent workers who enjoy more favorable employment opportunities than the outsiders. The reason for this disparity is that firms incur labor turnover costs when they replace insiders with outsiders. Examples of labor turnover costs are the costs of hiring, firing and providing firm-specific training. ${ }^{5}$ In labour economics, insider-outsider theory examines the behaviour of corporate agents on markets on which only certain participants have privileged positions in relation to one another, as is the case of enterprises having a quality system. Such theory has been developed by Assar Lindbeck and Dennis Snower.
} 
It is obvious that the use of such unrealistic information made available to a wide audience by a company that has implemented a quality system would lead in the research to results of no practical use. In order to avoid such situations, the methodology we have used has been completed by the interviews granted by quality assurance managers of the enterprises where we have conducted our documenting. We consider that the use of such interviews, which have been made so that we could gather the intended information from each enterprise, have made the difference between our research and typical questionnaire-based research. The underlying reasoning is that interviews are interactive, flexible and they allow in-depth discussions and focused exploration. Apart from that, they allow a verification of the information they obtain and they lead to a clarification of terminology and an adjustment of specific knowledge and experience based on the interviewed subject.

Of course, the interview presents disadvantages, depending on the manner of approach. We refer here to the necessity that the interviewed subjects should possess the proper skills and know-how, to the difficulty of obtaining precise answers or lacking motivation of the interviewees within the talks. In spite of the methodological similarity, this research differs in several important aspects from typical empirical research on financial events. Firstly, this research does not focus on the information event effect (of "advertisement" type) on the capital market. Secondly, event data are not obtained mainly from information published to the wider public, but rather from private information obtained from interviews as a result of documenting on the spot. Thirdly, the targeted phenomenon (that of implementing the quality system) does not take place at a certain point in time, as a typical announcement, but it occurs during a period of time extending over a few years. This specific to the phenomenon that is subject matter of our research (quality system). The reason for this is that while a few of its benefits, such as the cost cutback can be obtained relatively quick, for many others, such as the increase of the market share as a result of customer satisfaction or labour productivity, at least a few years are necessary in order to become obvious in the data of the corporate accounting.

Obviously, we have tried to use the experience of other authors that have already performed such research, as available in the literature in this field, but some of them have been inconvenient, because most of such research do not focus directly and so such extent on IQMS, but rather on events such as the winning of a prize for quality assurance (Hendricks and Singhal 1996) or the obtaining of a certificate of the standard group ISO 9000 (Anderson, Daly and Johnson 1995) etc. This is why we consider that our research, by which we examine the impact of IQMS and IMSCQM on the financial performance of an industrial organization is novel and it brings about both an improvement of approaches so far in the literature in this field as well as a useful instrument for the managers of organizations who want to analyse the efficiency of the implemented quality system.

The analysis of methodology we have proposed, based on corporate financial ratios has limitations as well, which we had to exceed both due to our documenting possibilities (all enterprises in which we have conducted our research, except for S.C. Cris-Tim S.A. are foreign-owned and they have offered us filtered information), and the targeted objective of this research - that of determining the efficiency of the quality system implementation and operation for industrial enterprises. We refer here to the fact that, by its system of ratios and in calculations performed, the methodology we have proposed does not evince all participants to the efforts and distribution of project effects for the implementation of the quality system. Participants both to efforts and to the results generated by the project represent a direct beneficiary, i.e. the enterprise and the "indirect" beneficiary, i.e. the state-represented society. This is why, in order to express all the efforts and effects that the implementation and operation of a quality system generates, the analysis of efficiency should be conducted on two levels, respectively at a microeconomic level (financial analysis) and a macroeconomic level, that of the company (business analysis). As a result, the financial analysis of the efficiency of the project for the implementation of the quality system must be applied at a corporate level (micro), where assessments are made at the level of the company's interests, i.e. the obtaining of a maximum profit to the allocated equity, as we have done in our case study.

When assessing revenues and expenses in financial analysis, taxes are to be considered as well as possible subventions from the state. Apart from that, prices charged are those on the market, both for products in the home land and imported goods. This is why any decision should be based on the result of business analysis as well.

Based on business analysis, the efficiency of the quality system shall be approached from the perspective of corporate interests. Such an approach is fair because the state has granted special attention to the implementation of quality systems, especially for SMEs, also offering financial support. This is why the state makes savings on the account of business agents who, based on their own funds, ensure environment protection, staff training and recycling as well as population health, they cut back on energy consumption, production costs and they increase 
labour productivity - all these with a favourable impact on the growth of competitiveness of national economy. Moreover, society is interested in consumer protection and the impact on the environment. This is why, in case a producer transfers a product with damaging characteristics to the social consumption process, such producer actually transfers its losses to the society, meaning that it is natural for society to come up with measures so that such product could be prevented from entering the market. We reached the same conclusions related to the quality system designed for environment protection or other systems that are based on the standards ISO 45001:2016, 22000, 50001 etc., where benefits are found mostly at society level. All such transfers of costs between business agents and national economy must be taken into consideration to the extent in which they can be quantified, as their contribution to the general results of the quality system implementation project is really important.

Based on such an approach, the opportunity and efficiency of the quality system is to be substantiated by a comparison of all efforts made for a proper functioning of the quality system, regardless of their origin, with the total results they generate on all levels, without taking into consideration who will be the beneficiaries of results.

In conclusion, regardless of such last notes on the possibility of improving methodology, we consider that the methodology we have developed in this research for an examination of the impact of a complex management phenomenon, such as the implementation of the quality management system is the most appropriate for the objective targeted by our research and it can represent an analysis model for business agents who want to know how quality systems contribute to an increase of corporate efficiency and competitiveness.

\section{Case study - application in an industrial company of the method that has been proposed for an assessment of management system efficiency}

The company on which we are going to exemplify the proposed method manufactures high-tech electronic goods and household appliances which are all meant for household use. It has 2,500 employees and a turnover of 384 million EUR for 2015. The company has implemented an integrated quality management system - ISO 9001:2008, ISO 14001:2005, ISO 50001:2011, which is accomplished in two stages: in 2006, it has implemented an integrated system made up of ISO 9001:2008, ISO 14001:2005, and in January 2014, it has implemented the standard ISO 50001:2011 as well, as it is a large consumer of electric energy. By the implementation of such three standards, the company has complied with the requirements imposed by its beneficiaries and by the companies with which it cooperates. The objective they have pursued by doing so has been a cutback to the minimum of the possibility that errors might appear and the reaching of a point when Zero Defects principle has been fulfilled. Apart from this integrated quality system, the company has also implemented, starting with 2014, further methods of the management system for continuous quality improvement - Kaizen. This is how the following methods have been integrated: 6 Sigma, Total Productive Maintenance and Just in Time.

On this company, we are going to accomplish a case study proposed in order to prove the efficiency of the implementation and operation of the integrated management system for continuous improvement of quality in industrial companies. We shall first analyse the impact of the implementation of the integrated quality system, which is made up of the three standards mentioned above, during 2006-2011, and then of the one generated by the action of the integrated system - IQMS, combined with the application of certain Kaizen methods, for the term 2011-2015 (respectively IMSCQM). In order that we could prepare this case study, we have used both the documenting made at the company we have selected, and the one conducted at several industrial organizations from Bucharest and from the rest of our country - which we have presented under point no. 2. Obviously, we have tried to use also the experience of other authors as well as researches we have found in the literature in this field, but certain drawbacks appeared as most of such researches do not focus directly and to such a great extent on IQMS, but rather on events such as the winning of a prize for quality assurance (Hendricks and Singhal 1996) or the obtaining of a certificate of the standard group ISO 9000 (Anderson, Daly and Johnson 1995) etc.

This is why we consider that our research, by which we examine the impact of IQMS and IMSCQM on the financial performance of an industrial organization, is novel and it brings about both an improvement of approaches so far in the literature in this field as well as a useful instrument for the managers of organizations who want to analyse the efficiency of the implemented quality system.

4.1. Analysis on the efficiency of the implementation of the integrated quality at the selected company during the time interval 2006-2011 
As we have presented under the point no. 4, in order that we could assess the quality system that is subject to our scrutiny, we shall use KPI ratios. For 2006, the simplified summary of the profit and loss account is presented under the table no. 2.

Balance sheet of the company as at December $31^{\text {st } 2006}$ Table no. $2^{6}$

\begin{tabular}{|l|l|l|l|}
\hline Indicator & Amount & Amount & $\begin{array}{l}\text { Turnover } \\
\text { percentage }\end{array}$ \\
\hline & TEUR $^{7}$ & TRON & $(\%)$ \\
\hline Turnover & 190,000 & $1,113,200$ & $100 \%$ \\
\hline Variable Costs & 114,750 & 673,200 & $60 \%$ \\
\hline Variable Cost Ratio (VCR) & 75,250 & 44,000 & $40 \%$ \\
\hline Fixed Costs & 66,500 & 397,454 & $35 \%$ \\
\hline Operating profit & 7,030 & 567,789 & $3,7 \%$ \\
\hline
\end{tabular}

With the help of such values, one can calculate the break-even point, according to the formula:

$$
B E P=\frac{F C}{V C R} x 100, \text { whereas: }
$$

BEP - break-even point; FC - fixed costs; VC - variable costs; VCR - variable cost ratio.

According to this formula, the break-even point expresses the minimum percentage of activity as reported to the production capacity, for which the profit is nil. Results show that, for the company that is subject to our analysis, the break-even point is $88.3 \%$ and in absolute values, it amounts to 166,250 thousand euro, i.e. 731,500 thousand RON.

$$
B E P=\frac{66,500}{75,250} x 100=88,3 \% \text { of the production capacity. }
$$

If a margin is used on variable costs, calculated as a percentage from turnover, the break-even point is obtained in value, i.e. the minimum turnover value for which the profit is nil. The formula is:

$$
\begin{aligned}
& B E P=\frac{F C}{V C R \%} \\
& B E P=\frac{66,500}{40 \%}=166,250 \text { Thousand euro, i.e. } 731,500 \text { thousand RON. }
\end{aligned}
$$

In the same year, total costs of non-quality have been quantified, as represented by the costs both of internal and external flaws, which amounted to 28,000 TEUR, an equivalent of $15 \%$ of turnover. This means in fact that actual variable costs are of only 75,250 x (100-15) $=63,963$ TEUR, while the difference of 11,287 TEUR represents non-quality costs. The successful introduction of the integrated quality management system lead to a significant improvement of indicators, which can be easily noticed if we browse the simplified form of the profit and loss account of the year 2011 (table no. 2).

As we can notice, the turnover value in euro reached 253 mil. The fact that the manufacturing process has been stabilized lead to a cutback of costs related to flaws, which was translated into a profit increase of $84 \%$ as compared to the year 2006. Results show that the break-even point is in $201190.3 \%$ and, in absolute values, it amounts to 225,825 TEUR, i.e. 993,634 TRON.

Concerning the inclusion in the time interval related to which the years of financial and economic crisis 2008 and 2009 is analysed, please note that it has not affected the results of our research, as the company did not bear any significant consequences, as financial indicators increased during such time. The turnover increased then by $133 \%$ and the profit increased by $183 \%$.

\subsection{Analysis of the efficiency of the implementation of the integrated management system for continuous quality improvement during the term 2011-2015}

\footnotetext{
${ }^{6} \mathrm{An}$ annual average exchange rate of 4.40 RON / EUR as per the accounting books of the company, for the entire period 2006-2015.

${ }^{7}$ Values in EUR are used as well for ratio calculation, so that comparison could be facilitated.
} 
Balance sheet of the company as at December $31^{\text {st }}$ 2011. Table no. 3

\begin{tabular}{|l|l|l|l|}
\hline Indicator & Amount & Amount & TO percentage \\
\hline & TEUR & TRON & $\mathbf{( \% )}$ \\
\hline Turnover & 253,000 & $1,113,200$ & $100 \%$ \\
\hline Variable Costs & 153,000 & 673,200 & $61,0 \%$ \\
\hline Variable Cost Ratio (VCR) & 100,000 & 44,000 & $39,0 \%$ \\
\hline Fixed Costs & 90,330 & 397,454 & $35,7 \%$ \\
\hline Operating profit & 12,905 & 567,789 & $5,1 \%$ \\
\hline
\end{tabular}

$B E P=\frac{90,330}{100,000} x 100=90,3 \%$ of the production capacity.

The result in absolute values is:

$B E P=\frac{90,330}{39 \%}=231,615$ Thousand euro, i.e. 1,091,000 thousand RON.

During the same year, total non-quality costs have been quantified, as represented by the cost both of internal and external flaws, which amounted to 23,276 TEUR, an equivalent of $9.2 \%$ of turnover. This means in fact that actual variable costs are of only $100,000 \times(100-9,2)=90,800$ TEUR, while the difference of 9,200 TEUR represents non-quality costs.

The successful introduction of the integrated quality management system and of methods of continuous quality improvement - Kaizen practically meant that the company got very near to the point of reaching its goal of zero defects, as it can be found from the table no. 3, where a simplified version of the profit and loss account for 2015 is presented.

As resulting from the table, the turnover reached 384,000 TEUR, which represents an increase of $152 \%$. The fact that the manufacturing process has been stabilized lead to a cutback of flaw-related costs, which materialized into a profit increase by 1.5 times as compared to the year 2011. This means that a decrease of $9.2 \%$ of flaw-related costs caused a profit increase of approximately 50\%. For 2015, the simplified profit and loss account is presented in the table no. 4 .

Balance sheet of the company as at December $31^{\text {st }} 2015$ Table no. 4

\begin{tabular}{|l|l|l|l|}
\hline Indicator & Amount & Amount & TO percentage \\
\hline & TEUR & TRON & $(\%)$ \\
\hline Turnover & 384,000 & $1,689,600$ & $100 \%$ \\
\hline Variable Costs & 230,400 & $1,013,760$ & $60 \%$ \\
\hline Variable Cost Ratio (VCR) & 153,600 & 675,840 & $40 \%$ \\
\hline Fixed Costs & 134,400 & 591,360 & $35 \%$ \\
\hline Operating profit & 19,200 & 84,480 & $5 \%$ \\
\hline
\end{tabular}

Results show that the break-even point of the company is $87.5 \%$ and, in absolute values, it amounts to 336,000 TEUR, i.e. $1,478,400$ TRON.

$$
B E P=\frac{134,400}{153,600} x 100=87,5 \% \text { of the production capacity. }
$$

Results for RON values of the break-even point i.e. the minimum turnover value for which profit is void: $B E P=\frac{134,400}{40 \%}=336,000$ Thousand euro, i.e. 1,478,400 thousand RON.

In the same year, total costs of non-quality have been quantified, as represented by the costs both of internal and external flaws, which amounted to 7,680 TEUR (i.e. 3 times lower than in 2011), an equivalent of $2.0 \%$ of turnover. As a result, actual variable costs are of only 153,600 x (100-2.0) $=150,528$ TEUR and the difference of 3,072 TEUR represents non-quality costs.

Such results express that, due to a successful introduction of the integrated quality management system combined with methods of the management system for continuous quality improvement - Kaizen, the position of the company is very close to the point of zero defects (within such result assessment we must note that the methods of Kaizen system have been present only during three years of the five-year time interval that was subject to our 
analysis). As a result, we consider that in the near future all industrial enterprises are going to pass to a quality system of the type we have analysed in this case study -integrated system of continuous quality improvement.

\section{Conclusions}

Concerning the role of quality management systems in quality assurance of goods and services delivered by companies and the increase of their competitiveness and based on the experience of our relations with business agents, we have reached the conclusion that there are numerous managers who are reluctant about quality systems, as they consider them an investment that is not covered by results, while quality per se is from their point of view just an element that reduces labour productivity. Such conclusion, which is obviously fallacious, is caused by the fact that they have not ensured the conditions that are necessary for an efficient use of quality systems.

The results of our research are convincing arguments proving that companies that implemented quality systems substantially improved the quality of their goods and have significantly increased the efficiency and competitiveness. This is why we consider that this research, by which we have examined the impact of IQMS and IMSCQM on the financial performance of an industrial company is novel and it brings about both an improvement of approaches so far in the literature in this field as well as a useful instrument for the managers of organizations who want to analyse the efficiency of the implemented quality system

\section{References}

Brunet, A.P. is New, S. (2003), Kaizen in Japan: an empirical study, International Journal of Operations \& Production Management, Vol. 23, No. 12, pp. 1426-46;

Casadesús, M.; Heras, I.; Karapetrovic, S. (2009), Los sistemas de gestio'n estandarizados:existen sinergias?, Revista Europea de Direccio'n y Economı'a de la Empresa, Vol. 18, No. 2, pp. 161-174;

Casadesús, M.; Heras, I.; Karapetrovic, S. (2007), Evolution of the Benefits and Costs of ISO 9001 Over Time, paper presented at $14^{\text {th }}$ International Annual Euroma Conference. Estambul;

Cheser, R.N. (1998), The effect of Japanese Kaizen on employee motivation in US manufacturing, The Journal of International Organizational Analysis, Vol. 6, No. 3, pp. 197-217;

Ionita, I. (2008), Quality Management and Value Engineering, ASE Printing House, Bucharest;

Ionita, I., Andrei, J. (2011), Measuring Value Romanian Experiences, Lambert Academic Publishing, Schaltungsdienst Lange Berlin;

Ioniţă, I. , Dobrin, C. Mieilă, M. - Model de proiectareşireproiectare a proceselorpentruimplementareaSistemului de management al calităţiiîn IMM, Revista de Economie general şiaplicată, nr.8/2006

Martí Casadesús, Stanislav Karapetrovic, Iñaki Heras, (2011) Synergies in standardized management systems: some empirical evidence, The TQM Journal, Vol. 23 Issue: 1, pp.73-86

Masaaki Imai (2006), Geamba Kaizen, Editura Finmedia, Bucuresti;

Rardin, Ronald L. (1997), Optimization in operations research. Prentice Hall. p. 919;

Van Aken, E.M., Farris, J.A., Glover, W. and Letens, G. (2010) A Framework for Designing, Managing, and Improving Kaizen Event Programs, International Journal of Productivity and Performance Management, Vol. 59, No. 7, pp. 641-667;

Suárez-Barraza, M.F., Ramis-Pujol, J. and Kerbache, L. (2011), Thoughts on kaizen and its evolution: Three different perspectives and guiding principles, International Journal and Lean Six Sigma, Vol. 2, No. 4, pp. 288-308. 